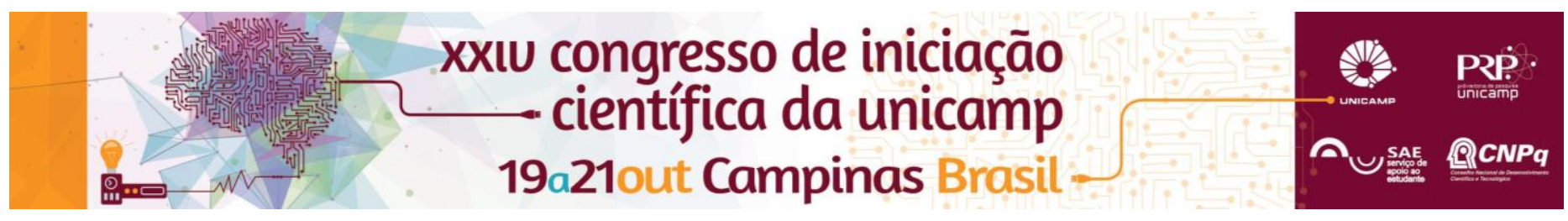

\title{
Otimização do processo Foto-Fenton para eliminação de corante em água
}

\author{
Mariana Geroto Sampaio*, Renato Falcão Dantas
}

\section{Resumo}

O processo foto-Fenton é uma tecnologia reconhecida por sua eficácia na degradação de contaminantes orgânicos. Entretanto, apresenta algumas desvantagens devido a sua faixa de $\mathrm{pH}$ ótimo de trabalho que se encontra em torno de 3. Muitas pesquisas têm sido feitas no sentido de desenvolver esssa tecnologia para a degradação de contaminantes orgânicos devido ao alto potencial dessa tecnica em produzir radicais eficientes na eliminação de contaminantes nocivos ao meio ambiente. Esse trabalho teve o objetivo de otimizar o tratamento para encontrar as condições de maior produção de radicais para ser empregado na eliminação de contantes. Os resultados demostraram que a concentração de peróxido foi a variável de maior significância no processo.

\section{Palavras-chave:}

Foto-fenton, esgoto sanitário, processos oxidativos avançados.

\section{Introdução}

O tratamento de efluentes é uma excelente estratégia de preservação do meio ambiente, pois protege os corpos receptores de contaminantes. ${ }^{1}$ Durante as reações de foto-Fenton, o peróxido de hidrogênio, íons de ferro e luz ultravioleta são combinado para a formação de radicais oxidantes com alto poder de eliminação de contaminantes e desinfecção. Nos últimos anos, se vem trabalhando no desenvolvimento desse processo a $\mathrm{pH}$ neutro usando quelatos para manter o Fe solúvel durante o tratamento em $\mathrm{pH}$ próximo a $7 .^{2}$

Nesse trabalho propõe-se o estudo da otimização do processo por meio de um planejamento fatorial com o objetivo de buscar uma maior produção de radicais oxidantes. Para isso utilizou-se a degradação do composto modelo azul de metileno.

\section{Resultados e Discussão}

Para a otimização do processo, foi utilizado um planejamento fatorial $2^{3}$. As variáveis testadas foram a concentração do composto azul de metileno, a concentração do peróxido de hidrogênio e a concentração do catalizador $\mathrm{Fe}^{2+}$. Como resposta foi utilizada a porcentagem de degradação do azul de metileno. Oito experimentos foram realizados em triplicata de acordo com a Tabela 1. Os experimentos foram realizados utilizando um reator com lâmpadas UV em seu interior, foi preparada $1 \mathrm{~L}$ de solução com água destilada, com a quantidade indicada em cada experimento de azul de metileno, ferro e o posterior ajuste do $\mathrm{pH}$ a $3 \mathrm{com}$ ácido sulfúrico. Para começar a degradação o peróxido de hidrogênio $\left(\mathrm{H}_{2} \mathrm{O}_{2}\right)$ foi adicionado a solução e as lâmpadas foram ligadas. A partir deste momento foram coletadas amostras em intervalos de 5 minutos, partindo de 0 até 30 minutos de degradação. Posteriormente a coleta, foi feita a leitura em espectrofotômetro com comprimento de onda $665 \mathrm{~nm}$. Com a curva de calibração construída, leu-se a absorbância e então a concentração de azul de metileno que foi degradada no processo foi determinada. Um exemplo da degradação do composto pode ser apreciado na Figura 1. De acordo com os resultados, as melhores porcentagens de degradação foram obtidas com a maior concentração de peróxido, sendo a concentração do catalisador e contaminantes pouco influentes na eliminação do Azul de metileno.
Tabela 1 - Variáveis utilizadas na otimização

\begin{tabular}{|c|c|c|c|}
\hline Experimentos & $\mathrm{Fe}^{2+}(\mathrm{mg} / \mathrm{L})$ & $\mathrm{H}_{2} \mathrm{O}_{2}(\mathrm{ml})$ & $\begin{array}{c}\text { Azul de } \\
\text { Metileno } \\
(\mathrm{mg} / \mathrm{L})\end{array}$ \\
\hline 1 & 2,7 & 0,1 & 10 \\
\hline 2 & 13 & 0,1 & 10 \\
\hline 3 & 2,7 & 0,2 & 10 \\
\hline 4 & 13 & 0,2 & 10 \\
\hline 5 & 2,7 & 0,1 & 5 \\
\hline 6 & 13 & 0,1 & 5 \\
\hline 7 & 2,7 & 0,2 & 5 \\
\hline 8 & 13 & 0,2 & 5 \\
\hline
\end{tabular}

Figura 1 - Degradação do Azul de Metileno. Experimento 5.

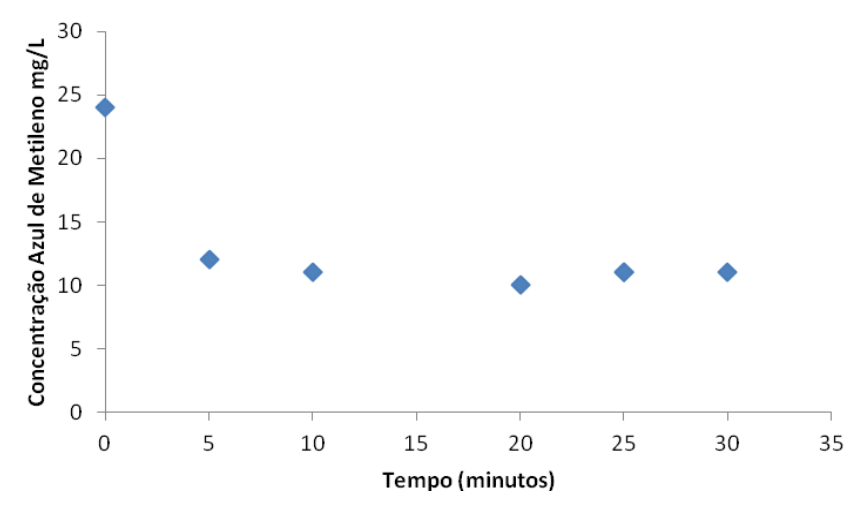

Conclusões

Ao final dos experimentos foi constatado que a concentração do oxidante é a principal variável a ser controlada. Os experimentos com a maior concentração de peróxido obtiveram melhores índices de degradação.

\section{Agradecimentos}

Os autores agradecem ao PIBIC e ao CNPQ pela bolsa de estudo.

1 Trapido M., Hirvonen A., Veressinina Y., Hentunen J., Munter R. (1997) Ozonation, Ozone/UV and UV/H2O2 degradation of chlorophenols. Ozone Sci. Eng.

2 Souza, B.S., Dantas, R.F., Barcelo, M.A., Lucena, F., Sans, C., Esplugas, S., Dezotti, M., Evaluation of UV/H2O2 for the disinfection and treatment of municipal secondary effluents for water reuse. J Chem Technol Biotechnol 2013; 88: 1697-1706. 